\title{
Estimation of the Wheat Losses Caused by the Tropospheric Ozone in Bulgaria and Denmark
}

\author{
Tzvetan Ostromsky ${ }^{1}$, Ivan Dimov ${ }^{1}$, Ilia Tzvetanov ${ }^{2}$, and Zahari Zlatev ${ }^{3}$ \\ ${ }^{1}$ Central Laboratory for Parallel Processing, Bulgarian Academy of Sciences \\ Acad. G. Bonchev str., bl. 25-A, 1113 Sofia, Bulgaria \\ ceco@cantor.bas.bg \\ dimov@copern.bas.bg \\ http://copern.bas.bg \\ 2 Institute of Economics of the Bulgarian Academy of Sciences \\ 3 Aksakov str., 1000 Sofia, Bulgaria \\ ineco@iki.bas.bg \\ ${ }^{3}$ National Environmental Research Institute, Department of Atmospheric \\ Environment \\ Frederiksborgvej 399 P. O. Box 358, DK-4000 Roskilde, Denmark \\ $z z @ d m u . d k$ \\ http://www.dmu.dk/AtmosphericEnvironment
}

\begin{abstract}
Long-term exposures to high ozone concentrations have harmful effect on the crops and reduce the yield. The exposures are measured in terms of AOT40 (Accumulated exposure Over Threshold of $40 \mathrm{ppb}$ ). The threshold of $40 \mathrm{ppb}$ has been accepted after several years of experimental research in open top chambers throughout Europe. As a result of these experiments a critical level of 3000 ppb.hours has been established for the crops. The sensitivity of the wheat to exposures above the critical level has been studied in more detail and a linear dependence between the relative yield and the AOT40 has been found. This relationship is used in the paper to estimate the wheat losses in Bulgaria and Denmark by regions in several consequtive years.

The Danish Eulerian Model is used to calculate the AOT40 values on the EMEP grid (a $96 \times 96$ square grid with step $50 \mathrm{~km}$., which covers Europe). The results on parts of this grid (covering Bulgaria and Denmark) are only used. In addition regional information about the actual yield and the prices is also needed for the target years. The algorithm for economical evaluation of the losses can be applied with different scenarios for partial reduction of the emissions and some other key parameters. The results can be used as a ground for a cost-benefit analysis of possible ozone reduction measures when effects on vegetation are studied.
\end{abstract}

\section{Introduction}

The damaging effects of high ozone concentrations on agricultural crops is known for a long time, but little was known until 1990 on the extent of these damages worldwide. Extended research on this problem has been conducted during

L. Vulkov, J. Waśniewski, and P. Yalamov (Eds.): NAA 2000, LNCS 1988, pp. 636-643, 2001.

(C) Springer-Verlag Berlin Heidelberg 2001 
the past ten years. Newly designed open top chambers (OTC) allow systematic study, leading to quantifiable estimates for use in policy analysis. To report on early progress, a number of meetings were carried out during the 1990's, e.g. in Switzerland in 1993 ([4]), and in Finland in 1995 ([6]). Among the recommendations from these meetings, a new parameter called AOT40 was introduced ([4] and [6]). This parameter was suggested to be applied to agricultural and economic assessments and subsequent modeling of benefits associated with reduced ozone exposure. The AOT40 parameter is commonly accepted now, also in the discussions of the forthcoming EU Ozone Directive (see $[1,3]$ ).

The value $40 \mathrm{ppb}$ is a practically determined threshold, below which the losses of crops due to ozone exposure could be neglected, and above which the losses are assumed to be linear with respect to the exposure. The choice of AOT40 is based on a large number of OTC experiments in Europe and in the United States.

In this work wheat losses in Bulgaria and Denmark for a period of ten years are calculated by using AOT40 values produced by the Danish Eulerian Model (DEM) $[10,11]$. Our work on these problems started a year ago [2]. Since then the model was improved significantly in its chemical part and in the vertical exchange through the boundary layers in accordance with the knowledge obtained by analyzing new measurement data. In addition a new release of emissions data from the EMEP inventories is used as an input in DEM now. All these developments lead to certain differences in the results, presented in this paper, in comparison with [2]. We believe our new estimates are much more accurate, although many uncertainties still remain.

\section{Data Sets Used in the Study}

The following data files are used in the calculations:

- The AOT40 values on the EMEP grid for each year in the period 1989 - 1998 (only the values on the parts of the grid covering Bulgaria and Denmark are used). These are produced by DEM and verified by comparisons with measurements and with results, obtained by other models. The maps with the AOT40 values over Bulgaria for 1990 and 1994 are shown in Fig. 1;

- The relationship between the AOT40 and the wheat loss, based on experiments in OTC, presented at meetings in Switzerland and Finland [5,4,7];

- The wheat yield in Bulgaria and Denmark by regions for the years under consideration, taken from the corresponding Statistical Yearbooks [8,9].

\section{Calculating the Losses by Regions}

The basic assumption behind introduction of the excess ozone concept and AOT40 in particular is that the relative yield of wheat linerly depends on the value of AOT40. Provided that $y$ is the actual yield, $y+z$ is the expected yield 

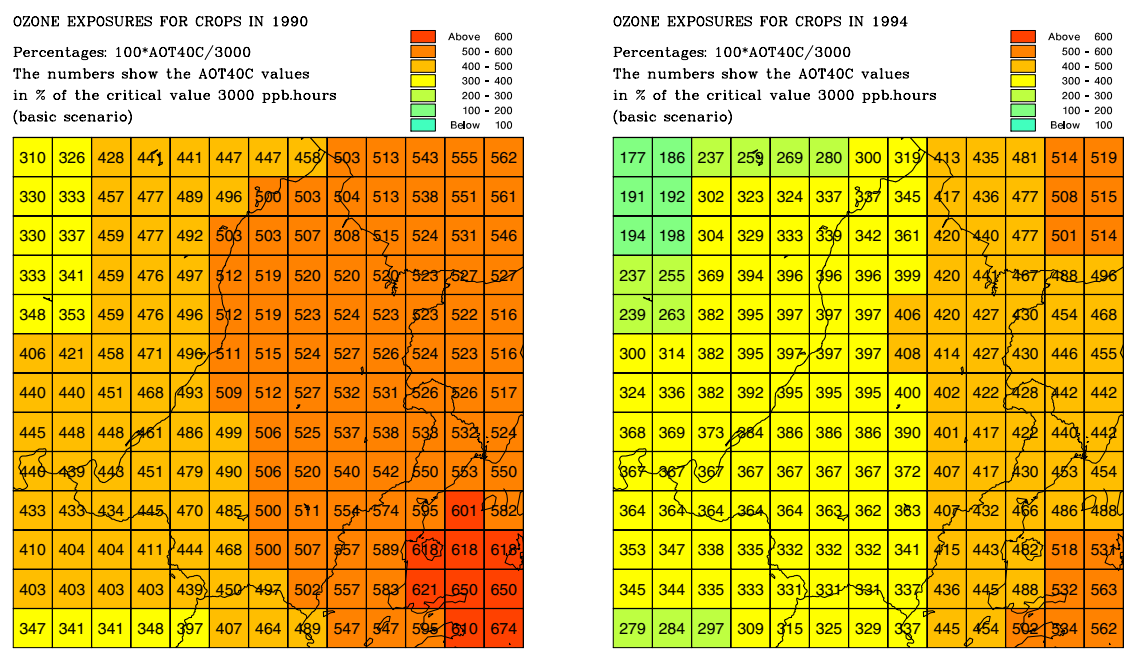

Fig. 1. AOT40 maps of Bulgarian region for 1990 and 1994

without any ozone exposure, $\xi$ is the AOT40 in ppb-hours, this linear regression can be expressed as follows:

$$
100 y /(y+z)=\alpha \xi+\beta \quad(\alpha<0, \quad \beta \approx 100)
$$

where $\alpha$ and $\beta$ are empirically determined coefficients. The values $\alpha=-0.00151$ and $\beta=99.5$, derived from OTC experiments performed in the Scandinavian countries, are used for calculating the losses in Denmark. The mean values, obtained by analyzing a wide set of OTC experiments representative for Europe, are $\alpha=-0.00177$ and $\beta=99.6$. The latter values are used in calculating the losses in Bulgaria. The specific coefficients for South-European countries (including Bulgaria) could be slightly different. Due to the small number of OTC experiments in these countries such specific coefficients cannot be determined yet. The above values are due to Pleijel [7].

Let us consider first a simplified (scalar) version of the task: to find the loss $z$ of given crop yield $y$ from a single region with a constant value $\xi$ of AOT40. The linear regression (1) gives the actual yield $y$ (in our task it is given) as a function of $x=y+z$, where $z$ is the unknown to be calculated.

$$
\begin{gathered}
y=\frac{(\alpha \xi+\beta)(y+z)}{100} \\
100 y=(\alpha \xi+\beta) y+(\alpha \xi+\beta) z \\
(100-\beta-\alpha \xi) y=(\alpha \xi+\beta) z \\
z=\frac{(100-\beta-\alpha \xi)}{(\alpha \xi+\beta)} y=f(\xi) y
\end{gathered}
$$


Consider now the real task: to find the losses from each of the $m$ regions of the country, covered by $n$ grid cells, taking into account that each region is covered by several grid cells with different value of AOT40. Denote by

$\Xi=\left(\xi_{j}\right)_{j=1}^{n}$ - the AOT40 vector $(m \times 1)$, per grid cell, calculated by the DEM;

$A$ - the regional division matrix $(m \times n)$;

$Y$ - the yield matrix $(m \times k)$, yields of $k$ crops per regions;

$Z$ - loss matrix $(m \times k)$, per regions - unknown

The calculations can be done in the following way (not unique):

$$
\Theta=\left(f\left(\xi_{j}\right)\right)_{j=1}^{n}, \quad S=A \Theta, \quad Z=\operatorname{diag}(S) Y
$$

Applying $f$ from (2) to $\Xi$ componentwise we find first the relative losses by grid cells $\Theta$ (with respect to the actual yields). The matrix-vector product $A \Theta$ gives the relative losses by regions $(S)$, and multiplying with them the rows of $Y$ we obtain the corresponding losses $Z$.

\section{Reduced Traffic Scenario}

Traffic is known to be one of the primary sources of ozone pollution in the developed countries. In order to evaluate the contribution of the traffic to the overall ozone pollution and the resulting economical losses, a scenario with $90 \%$ reduction of the actual traffic emissions is included in our study. This scenario is called hereafter traffic scenario, unlike the basic scenario, which denotes the actual situation and the corresponding actual losses. The traffic scenario is applied to the same 10-year period and the corresponding AOT40 values are calculated by using the Danish Eulerian Model $[10,11]$. The flexibility of the model allows us to calculate these values by proper reduction of the actual emissions and keeping all the other input data unchanged. Simple calculations show that the traffic scenario leads approximately to the following global reductions of the anthropogenic emissions:

- $45 \%$ reduction of the anthropogenic $N O_{x}$ emissions;

- $40 \%$ reduction of the anthropogenic VOC emissions;

- $54 \%$ reduction of the anthropogenic $C O$ emissions;

- no change in the anthropogenic $\mathrm{SO}_{2}$ and $\mathrm{NH}_{3}$ emissions as well as in all biogenic emissions.

The results for the estimated wheat losses in Bulgaria and Denmark, obtained both with the basic and the traffic scenario, are given in the next two sections.

\section{Estimated Wheat Losses in Bulgaria}

Numerical results for the estimated wheat losses due to high ozone levels in Bulgaria during a ten-year period (1989 - 1998) are presented in this section. 
Table 1. Ozone-caused wheat losses in Bulgaria for 1990

\begin{tabular}{|l|r||rr|rr|r|}
\hline \multicolumn{2}{|c||}{ Wheat yield in 1990 } & \multicolumn{4}{c|}{ Losses of wheat (in thousand tons and \%) } \\
\hline \multicolumn{1}{|c||}{ Region } & Yield & Basic scenario & Traffic scenario & Savings \\
\hline \hline 1 Sofia City & 34.5 & 12.7 & $26.9 \%$ & 8.6 & $19.9 \%$ & 4.1 \\
2 Burgas & 671.1 & 231.7 & $25.7 \%$ & 161.6 & $19.4 \%$ & 70.1 \\
3 Varna & 1257.2 & 430.4 & $25.5 \%$ & 300.7 & $19.3 \%$ & 129.7 \\
4 Lovech & 802.4 & 285.0 & $26.2 \%$ & 199.2 & $19.9 \%$ & 85.8 \\
5 Montana & 667.9 & 276.9 & $29.3 \%$ & 199.6 & $23.0 \%$ & 77.3 \\
6 Plovdiv & 277.7 & 105.6 & $27.5 \%$ & 75.8 & $21.4 \%$ & 29.8 \\
7 Russe & 887.7 & 350.0 & $28.3 \%$ & 253.5 & $22.2 \%$ & 96.5 \\
8 Sofia & 209.8 & 79.0 & $27.4 \%$ & 56.5 & $21.2 \%$ & 22.5 \\
9 Haskovo & 483.8 & 173.6 & $26.4 \%$ & 125.1 & $20.5 \%$ & 48.5 \\
\hline Whole country & 5292. & 1945.0 & $26.9 \%$ & 1380.6 & $20.7 \%$ & 564.4 \\
\hline
\end{tabular}

Table 2. Ozone-caused wheat losses in Bulgaria for 1994

\begin{tabular}{|l|r||rr|rr|r|}
\hline \multicolumn{2}{|c||}{ Wheat yield in 1994 } & \multicolumn{5}{c|}{ Losses of wheat (in thousand tons and \%) } \\
\hline \multicolumn{1}{|c||}{ Region } & Yield & Basic scenario & Traffic scenario & Savings \\
\hline \hline 1 Sofia City & 26.9 & 7.5 & $21.8 \%$ & 5.0 & $15.5 \%$ & 2.5 \\
2 Burgas & 442.3 & 105.9 & $19.3 \%$ & 74.4 & $14.4 \%$ & 31.5 \\
3 Varna & 956.4 & 251.5 & $20.8 \%$ & 176.5 & $15.6 \%$ & 75.0 \\
4 Lovech & 485.1 & 128.5 & $20.9 \%$ & 90.7 & $15.7 \%$ & 37.8 \\
5 Montana & 469.6 & 133.1 & $22.1 \%$ & 99.3 & $17.5 \%$ & 33.8 \\
6 Plovdiv & 209.6 & 58.9 & $21.9 \%$ & 43.0 & $17.0 \%$ & 15.9 \\
7 Russe & 664.0 & 189.2 & $22.2 \%$ & 137.0 & $17.1 \%$ & 52.2 \\
8 Sofia & 143.4 & 40.4 & $22.0 \%$ & 29.4 & $17.0 \%$ & 11.0 \\
9 Haskovo & 357.0 & 95.7 & $21.1 \%$ & 71.4 & $16.7 \%$ & 24.3 \\
\hline Whole country & 3754. & 1011.0 & $21.2 \%$ & 726.7 & $16.2 \%$ & 284.3 \\
\hline
\end{tabular}

Table 3. Ozone-caused wheat losses in Bulgaria for 1998

\begin{tabular}{|l|r||rr|rr|r|}
\hline \multicolumn{2}{|c||}{ Wheat yield in 1998 } & \multicolumn{5}{c|}{ Losses of wheat (in thousand tons and \%) } \\
\hline \multicolumn{1}{|c||}{ Region } & Yield & Basic scenario & Traffic scenario & Savings \\
\hline \hline 1 Sofia City & 32.4 & 10.4 & $24.3 \%$ & 5.8 & $15.2 \%$ & 4.6 \\
2 Burgas & 452.4 & 122.1 & $21.3 \%$ & 68.0 & $13.1 \%$ & 54.1 \\
3 Varna & 733.7 & 219.7 & $23.0 \%$ & 121.0 & $14.2 \%$ & 98.7 \\
4 Lovech & 455.4 & 151.0 & $24.9 \%$ & 87.4 & $16.1 \%$ & 63.6 \\
5 Montana & 326.2 & 97.8 & $23.1 \%$ & 61.3 & $15.8 \%$ & 36.5 \\
6 Plovdiv & 217.8 & 71.4 & $24.7 \%$ & 40.3 & $15.6 \%$ & 31.1 \\
7 Russe & 547.7 & 182.6 & $25.0 \%$ & 111.6 & $16.9 \%$ & 71.0 \\
8 Sofia & 132.0 & 42.5 & $24.4 \%$ & 24.3 & $15.6 \%$ & 18.2 \\
9 Haskovo & 315.2 & 96.9 & $23.5 \%$ & 57.3 & $15.4 \%$ & 39.6 \\
\hline Whole country & 3213. & 994.0 & $23.6 \%$ & 577.0 & $15.2 \%$ & 417.0 \\
\hline
\end{tabular}

The results for 1990, 1994, 1998 are presented in more detail in Tables 1, 2 and 3. In Table 4 the mean values for the ten-year period under consideration are given. 
Table 4. Average ozone-caused wheat losses in Bulgaria for the period 1989 1998

\begin{tabular}{|l|r||rr|rr|r|}
\hline \multicolumn{2}{|c||}{ Average yield (1989-98) } & \multicolumn{4}{c|}{ Average losses (in thousand tons and \%) } \\
\hline \multicolumn{1}{|c||}{ Region } & \multicolumn{1}{|c|}{ Yield } & Basic scenario & Traffic scenario & Savings \\
\hline \hline 1 Sofia City & 21.1 & 7.4 & $26.0 \%$ & 5.1 & $19.6 \%$ & 2.3 \\
2 Burgas & 485.4 & 131.0 & $21.3 \%$ & 96.4 & $16.6 \%$ & 34.6 \\
3 Varna & 871.4 & 253.5 & $22.5 \%$ & 186.5 & $17.6 \%$ & 67.0 \\
4 Lovech & 465.6 & 141.4 & $23.3 \%$ & 103.7 & $18.2 \%$ & 37.7 \\
5 Montana & 391.5 & 136.2 & $25.8 \%$ & 103.7 & $20.9 \%$ & 32.5 \\
6 Plovdiv & 237.9 & 70.8 & $22.9 \%$ & 53.2 & $18.3 \%$ & 17.6 \\
7 Russe & 593.1 & 199.3 & $25.2 \%$ & 150.0 & $20.2 \%$ & 49.3 \\
8 Sofia & 141.1 & 42.6 & $23.2 \%$ & 31.8 & $18.4 \%$ & 10.8 \\
9 Haskovo & 356.1 & 107.9 & $23.3 \%$ & 81.6 & $18.7 \%$ & 26.3 \\
\hline Whole country & 3563. & 1090.0 & $23.4 \%$ & 812.2 & $18.6 \%$ & 277.8 \\
\hline
\end{tabular}

The yield of wheat (in thousand tons) in the Bulgarian regions as well as in the whole country is given in column 2 of these tables. The estimated wheat losses (in thousand tons and \%) are given in the third column. The virtual losses in case that the traffic emissions in Europe are reduced by $90 \%$ are given in the next column, and the corresponding savings (in thousand tons) are given in the last column of the tables.

\section{Estimated Wheat Losses in Denmark}

The wheat losses in Denmark (by regions as well as for the whole country) have also been studied. Instead of tables the losses (in \%) for 1990, 1994, 1998 and the average values for the period $1989-1998$ are presented as plots in Fig. 2. The percentages of losses in Denmark are about twice as small as those in Bulgaria, because of the lower AOT40 values for Denmark. The losses in Denmark seem to be more sensitive to reduction of the traffic emissions, as seen from the results for the Traffic scenario (the right-hand side plots in the figure).

\section{Concluding Remarks}

The results reported in this paper indicate that the current levels of AOT40 are causing rather big losses of the wheat yield, especially in Bulgaria. The study has been carried out over a time interval of ten years (1989-1998). The amount of losses varies considerably from one year to another. The variations are caused both by the fact that the meteorological conditions are changing from one year to another and by the fact that the European anthropogenic emissions were gradually reduced in the studied ten-year period.

The effect of reduction of the traffic emissions is stronger in Denmark, compared to Bulgaria. This can be explained with the higher gradient of the AOT40 

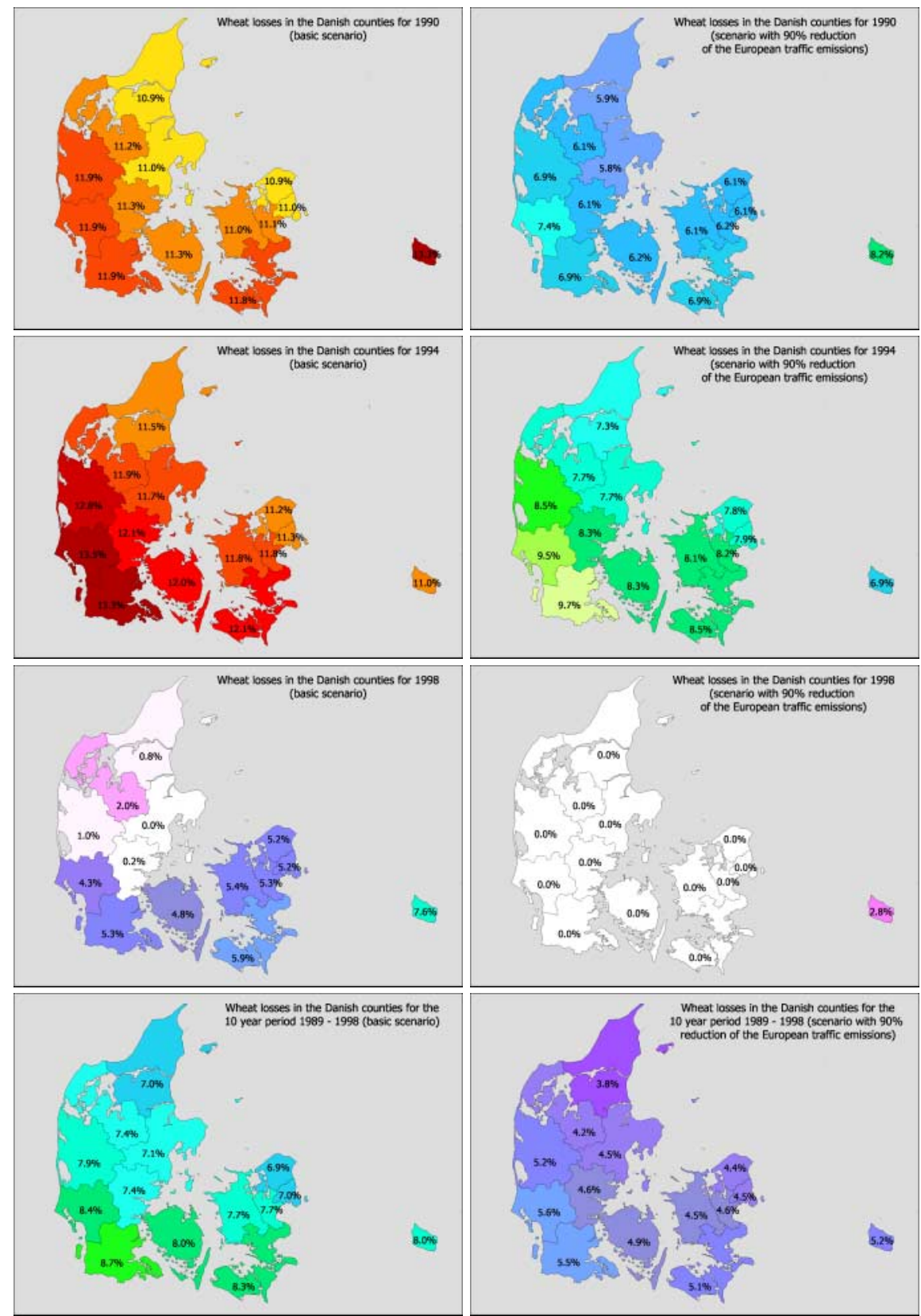

Fig. 2. Wheat losses in the Danish regions under the Basic scenario (left plots) and the Traffic scenario (right plots) for 1990, 1994, 1998, and the average losses for the period 1989-98 
values over Denmark due to its location between the zone of high ozone levels around German-Polish border and the zone of clean air over Central Scandinavia.

This work can be generalized in at least two directions. The method and the algorithms described can easily be adjusted to cover other countries or groups of countries, even whole Europe. They can also be used to calculate the total agricultural losses from the ozone exposure, taking into account the various sensitivity of different types of crops. The main obstacles are obtaining the necessary input data as well as the lack of experimental study on the sensitivity of a wider variety of crops to ozone exposure.

\section{Acknowledgments}

This research was partially supported by NATO under projects ENVIR.CGR 930449 and OUTS.CGR.960312, by the EU ESPRIT projects WEPTEL (\#22727) and EUROAIR (\#24618), and by the Ministry of Education and Science of Bulgaria under grants I-811/98 and I-901/99. It is also partly supported by a grant from the Nordic Council of Ministers. A grant from the Danish Natural Sciences Research Council gave us access to all Danish supercomputers.

\section{References}

1. M. Amann, I. Bertok, J. Cofala, F. Gyartis, C. Heyes, Z. Kilmont, M. Makowski, W. Schöp and S. Syri. Cost-effective control of acidification and ground-level ozone. Seventh Interim Report of IIASA, A-2361 Laxenburg, Austria, 1999. 637

2. I. Dimov, Tz. Ostromsky, I. Tzvetanov, Z. Zlatev. Economical Estimation of the Losses of Crops Due to High Ozone Levels. In Notes on Numerical Fluid Mechanics, Vol.73, 2000, pp. 275-282. 637

3. Position paper for ozone. European Commission, Directorate XI: "Environment, Nuclear Safety and Civil Protection", Brussels, 1999. 637

4. J. Fuhrer and B. Achermann (eds.). Critical levels for ozone. Proc. UN-ECE Workshop on Critical Levels for Ozone, Swiss Federal Research Station for Agricultural Chemistry and Environmental Higyene, Liebefeld-Bern, Switzerland, 1994. 637

5. J. Fuhrer, L. Skarby and M. R. Ashmore. Critical levels for ozone effects on vegetation in Europe. Environmental Pollution, Vol.97, 1-2, 1997, pp. 91-106. 637

6. L.Karenlampi and L. Skarby (eds.). Critical Levels for Ozone in Europe: Testing and Finalizing the Concepts. Proc. UN-ECE Workshop on Critical Levels for Ozone, University of Kuopio, Finland, 1996. 637

7. H. Pleijel. Statistical aspects of critical levels for ozone based on yield reductions in crops. In "Critical Levels for Ozone in Europe: Testing and Finalizing the Concepts" (L.Karenlampi and L. Skarby, eds.), University of Kuopio, Finland, 1996, pp. 138-150. 637, 638

8. Statistical Yearbook of Bulgaria, Vol. 90, ...99, Statistical Institute - BAS, Sofia 637

9. Statistisk Årbog - Danmark, Vol. 90, . . 99, Danmarks Statistic, Copenhagen. 637

10. Z. Zlatev, J. Christensen and Ø. Hov, An Eulerian model for Europe with nonlinear chemistry, J. Atmos. Chem., 15, 1992, pp. 1-37. 637, 639

11. Z. Zlatev, I. Dimov and K. Georgiev, Studying long-range transport of air pollutants, Computational Sci. \& Eng., 1, 1994, pp. 45-52. 637, 639 